\title{
The Distribution and Cultural Context of Artificial Cranial Modification in the Central and Southern Philippines
}

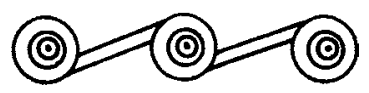

\author{
JAMIE L. CLARK
}

\section{INTRODUCTION}

ARTIFICIAL CRANIAL MODIFICATION (ACM) results primarily from the application of various apparati such as boards or cloth bindings to an infant's skull and is evidenced by changes in the shape of the head that can range from mild to extreme. Ethnographic and historic sources indicate that the practice of ACM typically begins within the first few days after birth (O'Loughlin 2004). As a permanent modification of the body imposed upon children by adults, the practice of ACM is of interest to archaeologists for its potential use in reconstructing past social systems. A wide range of cultural groups from the Songish of British Columbia to the Arawe of Melanesia have considered a deformed head a mark of beauty (Blackwood and Danby 1955; Boas 1891). Beyond purely aesthetic reasons, ACM can serve as an important means of defining and signaling social identity. While it has long been recognized that cranial modification is a significant cultural artifact (e.g., Dingwall 1931), archaeological research on the cultural context of ACM, particularly its role in defining group membership, has been more recent (e.g., Blom 2005; Fletcher et al. 2008; Garrett 1988; Hoshower et al. 1995; Torres-Rouff and Yablonsky 2005). This surge of interest is likely due in part to the growing focus on archaeological explorations of ethnicity and social identity more broadly (e.g., Jones 1997; Stark 1998).

Thus far, explorations into the social context of ACM have primarily focused on samples from the New World (e.g., Blom 2005; Garrett 1988; Hoshower et al. 1995; Lozada 1998; Torres-Rouff 2002; but see Fletcher et al. 2008); however, the long history of interest in ACM in the Philippines suggests that the region could also serve as an appropriate focus for an examination of the cultural context of the practice. The earliest discussion of ACM in the Philippines is attributed to Father Diego Bobadilla, who in 1640 reported that people in the central Philippines placed the "heads of their children between two flat boards upon birth, and they pressed [the boards] so that [the skull] would extend . . . and flatten the forehead, thinking that this was a trait of

Jamie L. Clark is an Assistant Professor, Department of Anthropology, University of Alaska Fairbanks. She is also an Honorary Research Fellow, Institute for Human Evolution, University of the Witwatersrand. 
beauty" (Dingwall 1931:130, translation by Veronique Belisle). According to Junker (1999: 124), a number of historic sources report that "membership in the nobility in some central Philippine groups was permanently marked at birth by cranial deformation: children of the elite class had their foreheads artificially flattened . . . as a mark of beauty and social distinction."

In his volume on the craniometry of the Philippines, Koeze (1903-1904) devoted an entire chapter to a discussion of ACM, arguing that it was most commonly practiced in the central Philippines, particularly in the Visayan Island group. More recently, discussions of ACM in the Philippines have been largely limited to noting the presence of deformed crania in archaeological site reports (e.g., MacDonald 1972; Tenazas 1973). Suzuki, Mioguchi, and Conese (1993) utilized a series of modified crania from the Philippines to explore the effects of ACM on craniofacial measurements; however, consideration of the cultural context of ACM was not necessary to their study.

The skeletal remains and associated artifacts from the University of Michigan's Philippine Expedition (hereafter referred to as the Guthe Collection) provide an excellent opportunity for examining the distribution and cultural context of ACM in the central and southern Philippines. The goals of this article are thus twofold. First, I examine the spatial distribution of the practice of ACM. Beyond providing further exploration of the hypothesis that ACM occurred more frequently in the central Philippines (particularly in the Visayan group [Koeze 1903-1904]) compared to the rest of the Philippines, the sample allows for a tentative evaluation of whether the practice of ACM was more common on particular islands within the study region. Second, I consider the artifactual material associated with the crania in order to examine the social context of artificial cranial modification in the Philippines. Through this analysis, I explore whether or not a connection can be drawn between ACM and elite status.

THE SAMPLE

As discussed by Sinopoli (this volume), the Guthe Collection is arguably the most important collection of Philippine archaeological materials and Asian trade ceramics in the United States. It also serves as an excellent sample for the study of ACM in the central and southern Philippines. The collection derives from the University of Michigan Philippine Expedition directed by Carl Guthe from 1922 to 1925. The goal of the expedition was to document and excavate sites in the central and southern Philippines, including most of the Visayan group, Mindanao, Palawan, and the Sulu Archipelago (Guthe 1929). Although the method of investigation was exploratory, the collection comprises provenienced artifacts and associated documentation from 542 archaeological sites (Guthe 1927). The sites, which were divided into four classes (graves, burial grounds, burial caves, and miscellaneous), span a range of dates, with the majority of Asian tradewares dating from the fourteenth to the sixteenth centuries (Bacus 1995; Dueppen, this volume; Li, this volume). Of particular interest for this study are the approximately 20 sites from which crania were recovered (Fig. 1).

Like many other excavations undertaken in the early twentieth century, a primary objective of the expedition was the recovery of exotic material-in this case, Chinese porcelains, celadons, and other Asian tradewares. This means that collection may have been biased in favor of these objects at the expense of more mundane items such as 


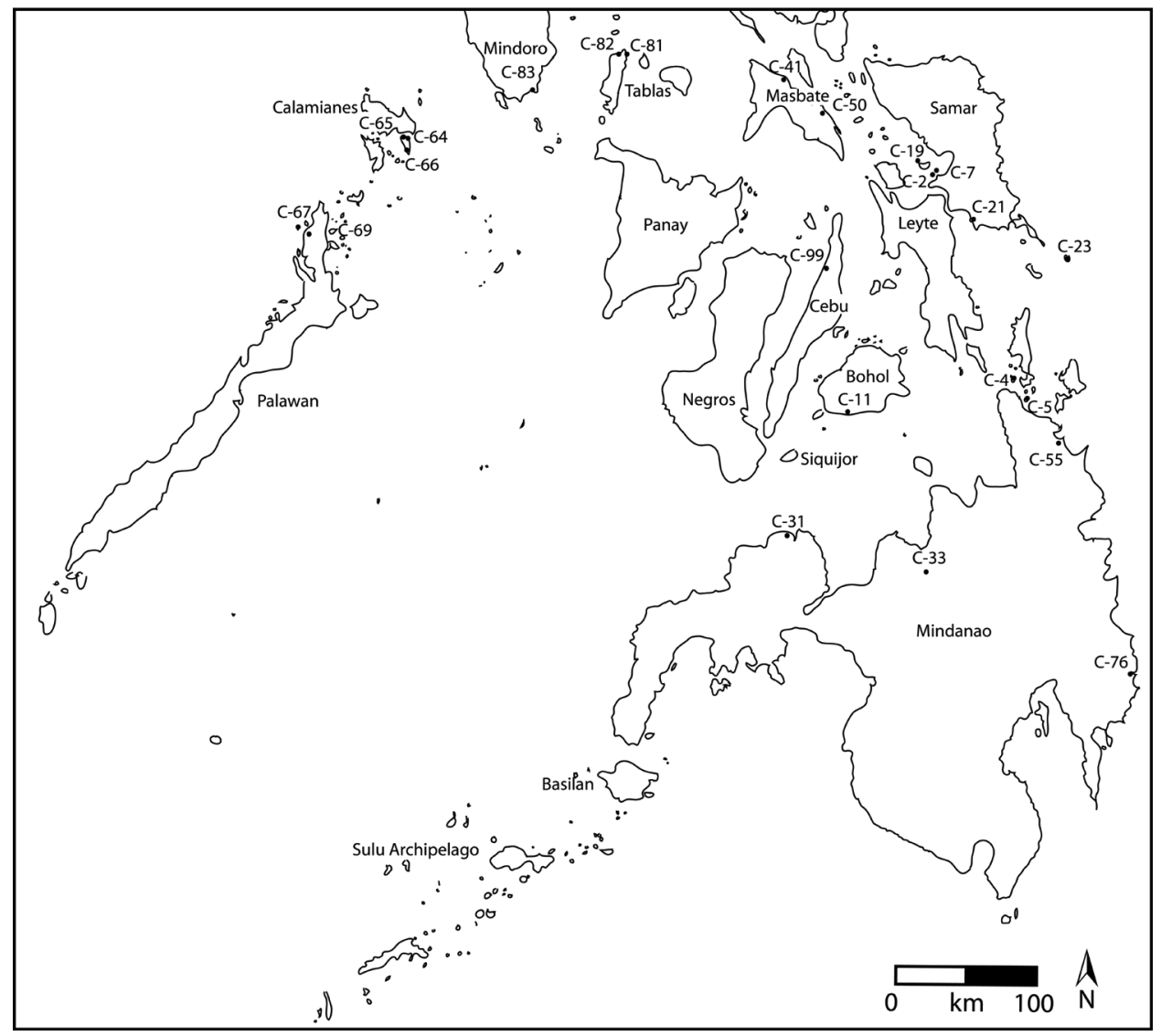

Fig. 1. Map of the central and southern Philippines showing location of burial caves from which crania were recovered.

locally produced earthenwares and osteological material. Guthe's (1922-1925) unpublished field notes from the University of Michigan Philippine Expedition suggest that this was, in fact, the case. There are several sites at which Guthe did not collect locally produced earthenware vessels, and he stated on numerous occasions that he aimed only to collect a "representative sample" of the "more perfect" skeletal material (Guthe 1922-1925, 1929). However, it is clear from Guthe's notes and publications that skulls were the skeletal element most likely to be saved, with modified crania holding special interest (Guthe 1922-1925, 1927, 1929). Because it is unlikely that Guthe left modified crania behind, the sample is seen as being sufficiently representative enough as to allow for an exploration of the geographic distribution of ACM in the central and southern Philippines.

Given that the material in the Guthe Collection was excavated in the 1920s, questions may be raised as to the quality of the documentation and excavation techniques. While Guthe's records provide relatively good provenience information for all of the site categories investigated, it is true that many of the sites were never visited by Guthe himself, but by "agents" employed by him. These sites are documented in less detail than those investigated by Guthe himself. However, it is fortuitous that the 
material used in this analysis derives from burial caves, as these were the sites at which Guthe conducted most of his own research. Guthe was in charge of the excavations at nearly every site under consideration, and, as a result, the field notes are generally quite detailed. While the excavations techniques he employed may not be entirely acceptable by today's standards, Guthe proved to be ahead of his time in several ways. For example, he used a sieve at several cave sites in the hopes of recovering beads and other small artifacts. Taken as a whole, the material utilized for this study represents some of the best excavated and most thoroughly documented of the expedition.

Because the Guthe Collection does not include material suitable for dating via radiocarbon analysis, a chronology based on ceramics provides the most feasible option for dating the excavated sites. In this case, the Asian tradewares provide the most promise in terms of developing a chronology. Over the last five decades, several important studies have been based on these wares (Aga-Oglu 1946, 1948, 1961; Bacus 1995). More recent work by Li Min (on blue-and-white porcelain, this volume), Stephen Dueppen (on stoneware dragon jars, this volume; see also Sinopoli et al. 2006), and Michael Maccheroni (2006) has helped to refine the chronology. However, an analysis of the complete collection of Asian tradewares in the Guthe Collection has not yet been undertaken. As a result, some sites have no dating information at all, and others have associated dates that must be taken with some caution, both because of the incomplete status of analysis and because of the complex problems relating to assemblage formation, which involves heirlooming (Dueppen, this volume) and the repeated use of and additions made to the burial caves. Although I make use of the chronologies provided by the above-mentioned ceramic studies, at present it is not possible to subdivide the skeletal remains chronologically. As a result, it is not yet possible to ascertain whether there is a temporal dimension to the distribution of ACM in the sample under consideration.

As previously mentioned, the material under consideration was recovered from burial caves. All of these caves appear to have been collective burial units and were likely used and added to over multiple generations. The practice of collective burial often results in loss of information about the primary treatment of individual burials (e.g., Keswani 1989), as earlier remains are disturbed by later burials and commemorative ritual acts. In addition, a large percentage of the sites were subject to postdepositional disturbance-either through looting, modern use, or water action (Guthe 1927). As a result, it is not possible to ascribe particular goods to particular individuals. Despite this, it does not seem unreasonable to assume that these sites represent socially cohesive groups, likely based on kin or clan relations (Andaya 1992; Keswani 1989). This means that it should be possible to discern patterns in artifact composition to the site level, which will be important in exploring the social context of ACM.

However, it is also important to note that the burial caves do not represent the full range of contemporary mortuary behaviors in the central and southern Philippines; as noted earlier, open air graves and burial grounds were also documented by the Philippine Expedition. The presence of similarly dated tradewares from all three types of burial sites indicates that they may have been used contemporaneously. Junker (1999) states that while caves continued to serve as burial sites into the early second millennium, the majority of cemeteries used at that time were open-air pit or log-grave burials of the type described in later Spanish accounts; in these accounts both commoners and elites were buried in open-air sites. At present, it is unclear whether burial caves were used by populations distinct from those that buried their dead in 
open-air sites, or whether the caves were used by particular subsets within the same populations (i.e., specific kin groups). I will return to this potential source of bias in my conclusion.

\section{CLASSIFICATION}

To explore the distribution and cultural context of ACM in the central and southern Philippines, it was first necessary to categorize the crania as either modified or unmodified. A combination of visual seriation and discriminant function analysis was utilized to classify the cranial sample. ${ }^{1}$ Sixty-eight crania were seriated on a grid laid out on two large lab tables; seriation was based upon the degree of frontal and occipital flattening, with occipital flattening scaled along one axis and frontal flattening along the other. This meant that unmodified crania (those with round frontal and occipital bones) clustered at the top left of the grid, while artificially modified crania (with flattened frontal and occipital bones) clustered in the bottom right corner (Fig. 2). Although it was expected that seriation would result in a linear arrangement of crania along a single axis from round/round to flat/flat, a number of crania clustered in the bottom left corner, showing occipital flattening but no discernable frontal flattening. These crania were placed into their own category called "round frontal/flat occipital." A number of crania were of ambiguous modification status, in that it was not clear whether the flattening evidenced was a product of artificial modification or was a part of the variation in cranial shape inherent in the population; these were also placed into their own category.

The largest group comprised unmodified crania $(\mathrm{N}=24)$. These were predominantly characterized by rounded frontal and occipital regions. Artificially modified crania $(\mathrm{N}=17)$ were identified based on the presence of significantly flattened frontal and occipital bones (Fig. 3). Although it appears that the deformation apparatuses employed were probably similar for all modified crania-likely consisting of boards or

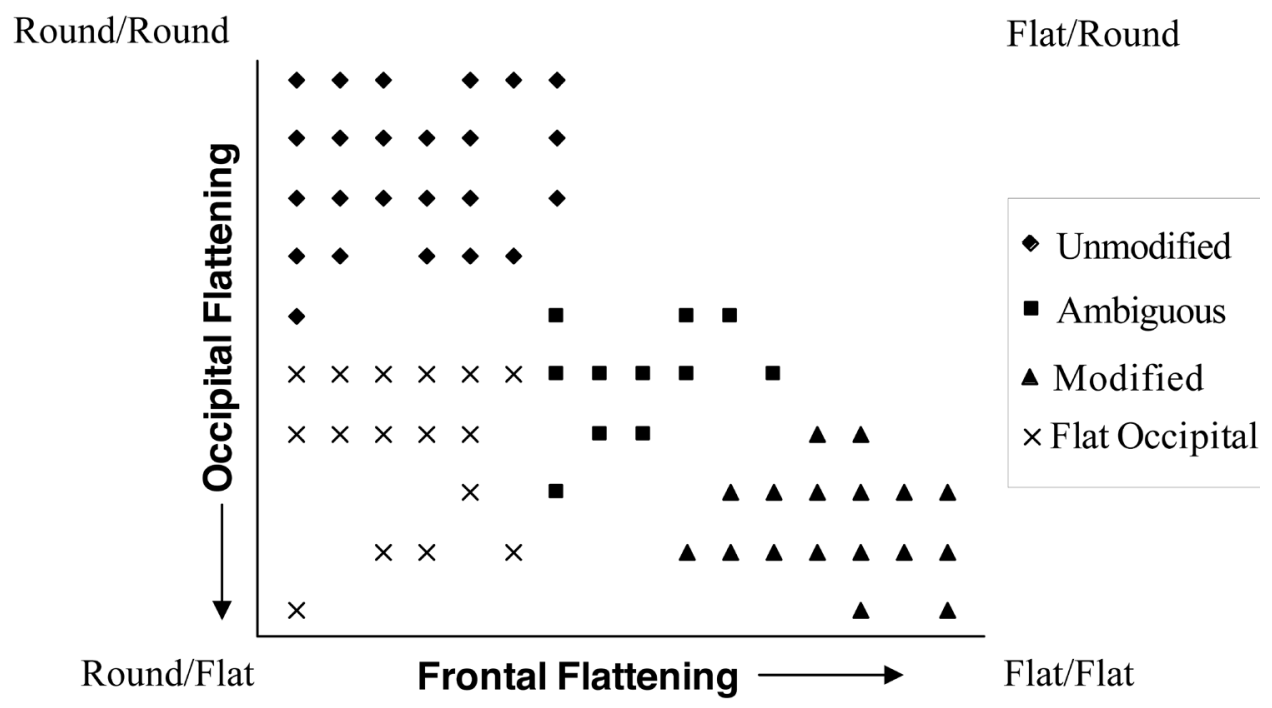

Fig. 2. Results of visual seriation (modified from Clark et al. 2007). 


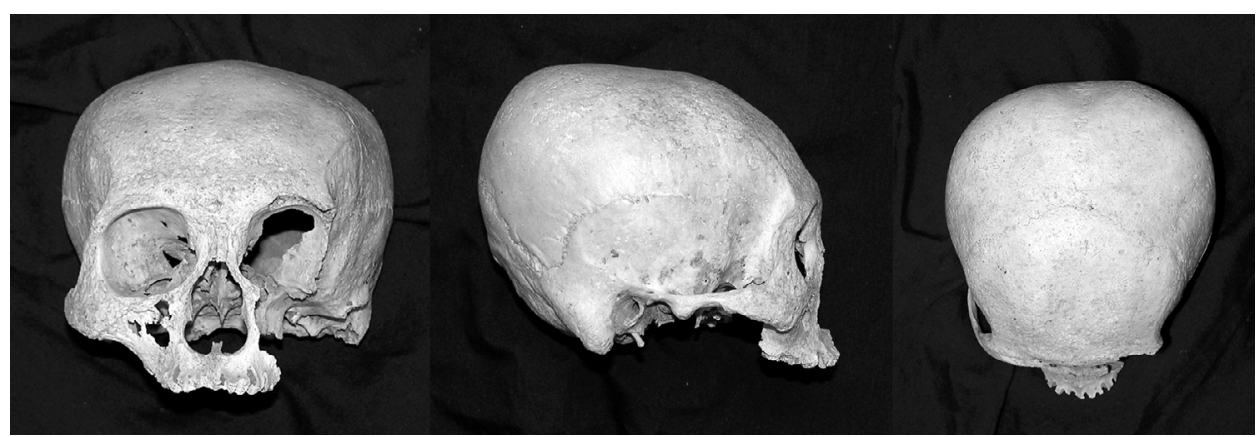

Fig. 3. Artificially deformed cranium from the Guthe Collection, UMMA Catalog \#34373.

stones strapped to the front and back of the skull-the artificially modified group shows a great deal of variability in degree and orientation of flattening. This may be a result of variation in the duration of application of the deforming apparatuses or in the angle at which the objects were bound to the skull. Sixteen crania were characterized by round frontal but flattened occipital bones. These crania were not classified as artificially modified due to the lack of involvement of the frontal bones. This form of modification was likely not intentional and may have resulted from cradle boarding, although ethnographic accounts documenting the practice of cradle boarding in the Philippines could not be located. Crania of ambiguous modification status $(\mathrm{N}=10)$ were of variable morphology, but all showed some degree of both frontal and occipital flattening.

Discriminant function analysis was utilized to confirm visual classification and to aid in the classification of ambiguous crania. Given that ACM results in flattening of the frontal and occipital regions as compared to unmodified crania (e.g., Anton and Weinstein 1999), curvature indices for the frontal, parietal, and occipital bones served as the discriminating variables for the function. The function was designed such that a negative score indicates that a cranium is unmodified while a positive score indicates that ACM is present. However, the function was designed to be conservative, meaning that while artificially modified crania may occasionally score as unmodified, unmodified crania should never receive a positive function score. Visual classification and discriminant function analysis disagreed for only three crania. These were visually classified as modified; however all three received negative function scores. Because each of these crania showed marked deformation, they retained their original classification for subsequent analysis (see Table 1 for sample sizes, before and after discriminant function analysis).

Given the conservative nature of the function, it seems reasonable to accept that the ambiguous crania that received positive scores were actually artificially modified. Two crania were thus transferred from the ambiguous to the deformed category. However, this same conservative approach implies that it is not certain that the ambiguous crania that scored as unmodified actually are, so that the crania remaining in this category were kept separate.

Given that all of the crania displaying round frontal but flattened occipital bones scored as unmodified, it would appear that the function does not identify practices such as cradle boarding in which the frontal bone is not involved. While recognizing 
Table i. Classification of Cranial Sample Based on Visual Seriation and Discriminant FUNCTION ANALYSIS

\begin{tabular}{lcc}
\hline & & AFTER DISCRIMINANT \\
& VISUAL CLASSIFICATION & 19 \\
FunCTION ANALYSI*
\end{tabular}

*Two crania from the "round frontal/flat occipital" group and one "ambiguous" cranium were removed from the study after the discriminant function analysis, as these were too incomplete for measurement and thus their deformation status was unclear.

that such morphology is likely due to a cultural practice, because this study is specifically concerned with the distribution and context of intentional cranial modification, this subset of the sample was combined with the "unmodified" group for subsequent analysis.

\section{THE SPATIAL DISTRIBUTION OF CRANIAL DEFORMATION}

As discussed, previous studies of ACM in the Philippines have indicated that the practice was most common in the central Philippines, particularly among the Visayan group (Beyer 1947; Koeze 1903-1904; Maceda 1973). This can be evaluated using the Guthe Collection, although any conclusions drawn from this sample must take into account the unsystematic nature of sample collection. It is also possible to explore whether ACM occurs more frequently on any particular islands within the sample set; these analyses are by necessity qualitative rather than quantitative. The relative frequency of each class of crania (modified, unmodified, and ambiguous) by island is presented in Table 2; this data indicates the presence of some potentially meaningful patterns.

As in previous analyses, ACM in this sample occurs predominantly in the Visayan Islands. This group comprises over 6000 islands, the largest of which are Samar, Ne-

Table 2. Distribution of Cranial Classes by Island

\begin{tabular}{lccc}
\hline ISLAND & MODIFIED & UNMODIFIED & AMBIGUOUS \\
\hline Bohol & 1 & 0 & 0 \\
Calamianes & 0 & 2 & 0 \\
Camotes & 0 & 1 & 0 \\
Cebu & 1 & 0 & 0 \\
Masbate & 1 & 6 & 0 \\
Mindanao & 1 & 11 & 0 \\
Mindoro & 0 & 2 & 0 \\
Palawan & 0 & 3 & 0 \\
Samar & 12 & 13 & 7 \\
Tablas & 3 & 38 & 1 \\
$\quad$ Totals & 19 & & 8 \\
\hline
\end{tabular}


gros, Cebu and Panay. Ninety-five percent (18/19) of the artificially modified crania in this sample were recovered from islands in that group. The only modified cranium not to come from the Visayas was found on Mindanao. Although modified crania have been identified throughout the Visayan Islands (Koeze 1903-1904; Maceda 1973; Suzuki et al. 1993), the results presented in Table 2 indicate that ACM may have been a more common practice on Samar and Tablas than on the other islands in this group. While it is possible this apparent pattern is a result of the nature of the expedition, wherein no islands were explored systematically and certain islands were subject to more thorough investigation than others, a number of factors indicate that this pattern may be a meaningful one.

First, given the variation in the manner and duration of the application of deformation apparatuses witnessed among populations in which ACM is practiced, one would expect to see a continuum from unmodified to highly modified crania in samples derived from such populations (Friess and Baylac 2003; Trinkaus 1982). This means that crania of ambiguous morphology should be more likely to occur in those places in which ACM was commonplace. In this case, not only do Samar and Tablas have the highest percentage of modified crania (among islands with a sample size greater than $n=1$ ), crania of ambiguous modification status are found only on these islands.

Furthermore, while Samar and Tablas account for only 16 percent of the total number of cave sites investigated (including those from which no crania were recovered), 79 percent of the modified crania were recovered from these two islands. That Samar and Tablas also account for 40 percent of all crania suggests that differential preservation may be a biasing factor. However, Guthe (1927) indicates that all cave sites were subjected to both water action and modern disturbance, and there is no indication in Guthe's (1922-1925) notes that the sites on Samar and Tablas were more or less disturbed than others. Furthermore, since a majority of the cave sites are located in karstic formations, there appears to be no underlying geologic reason why preservation would be better on these two islands. Given that Samar and Tablas are also widely separated in space relative to the rest of the sample, there is no obvious reason to expect that skeletal material would be better preserved at these locations (Guthe 1922-1925, 1927). The spatial data thus suggests that ACM may have been practiced at higher frequencies among populations on Samar and Tablas, although larger samples from well-excavated contexts will be necessary to establish the validity of this pattern.

\section{THE CULTURAL CONTEXT OF CRANIAL DEFORMATION}

In order to explore the hypothesis that ACM was an elite practice in the central and southern Philippines, it was first necessary to identify what artifact classes have been associated with elite activities and burials in the Philippines. Junker (1999:3) reports that as early as the beginning of the first millennium A.D., the Philippines had become part of a vast trade network in which Chinese, Southeast Asian, Indian, and Arab traders circulated porcelains, silks, glass beads, and other luxury goods throughout the region. Such luxury goods, she argued, became key symbols of social prestige for the Philippine chiefly elite. Other elements of status insignia included gold ornaments, ivory, silver, semiprecious stones, gold-pegged teeth, metal weaponry, and elaborate tattoos. These items appear to have been subject to limited distribution controlled by 
the elite. To that list, Bacus (1995) adds decorated earthenware-although it is unlikely that all decorated earthenware were prestige items, excavations at the site of Tanjay indicate that at least some of this class of artifact show restricted distribution within the context of complex polities. Another form of personal ornamentation that may be associated with elevated status is shell jewelry, although this has been debated (Junker 1999). Of these artifact classes, some (such as silk garments and tattooing) will not survive to become part of the archaeological record; however, the remainder of these artifact types should be recoverable.

Table 3 presents information on the presence of elite goods at each site from which crania were recovered. The list begins with those sites in which ACM is present, organized by island and then by site number. Of the elite goods previously mentioned, semiprecious stones, ivory, and silver are completely absent within the present sample. Thus, the table is limited to the following classes: gold ornaments, gold-pegged teeth, Asian tradeware, decorated earthenware, metal weaponry, shell jewelry, and glass beads.

The final column in Table 3 provides estimated dates of use for those sites for which dates are available. Because the sites were communal burials whose use may have spanned hundreds of years, and given the lack of stratigraphic information from the excavations, these dates do not represent duration or intensity of site use, but simply provide a general time frame during which the site saw some use. The lack of a refined chronology for the Guthe Collection does affect the interpretation of the data presented in Table 3. Junker (1999) has argued that access to exotic trade goods was most restricted from the tenth to the fourteenth centuries. By the fifteenth century, an expanding maritime trade had widened the distribution of these goods to the point that they appear archaeologically in some low-status habitations and burial areas ( $\mathrm{Li}$, this volume).

In his analysis of blue-and-white Chinese porcelains from the Guthe Collection, Li (this volume) demonstrates a decline in both quality and quantity of these wares from cave contexts in the fifteenth century. Furthermore, Li argues that while the caves were used as burial grounds by those who considered the possession of fine porcelains to indicate wealth and status, no particular cave site stands out as having a significantly greater concentration of fine blue-and-white porcelains, which may indicate a weak expression of wealth distinctions during this period. In either case, it would appear that on their own, porcelains dated to the Ming Dynasty may not be indicative of elite status.

To explore the hypothesis that ACM was an elite practice, a Mann-Whitney test was conducted based on the number of elite artifact classes present at each site. The goal of this test was to explore whether the number of elite artifact classes occurring at sites in which ACM was present was greater than that at sites showing no evidence of modified crania. The results were not significant at $\alpha=.05$, with $p=.432$. Thus, the available evidence indicates that sites at which artificial deformation is present do not show a greater co-occurrence of elite artifact classes, suggesting that the practice of deformation may not have been limited to the elite.

While Table 3 presents site-level data, Table 4 breaks down the presence/absence of data for each artifact class into two categories: sites where ACM is present and sites where it is not. Fisher's Exact Test was applied to each class of elite artifacts in order to test whether each class occurred at greater frequencies at sites where ACM was present; these results are shown in the final column of Table 4. At an alpha level of .05, 


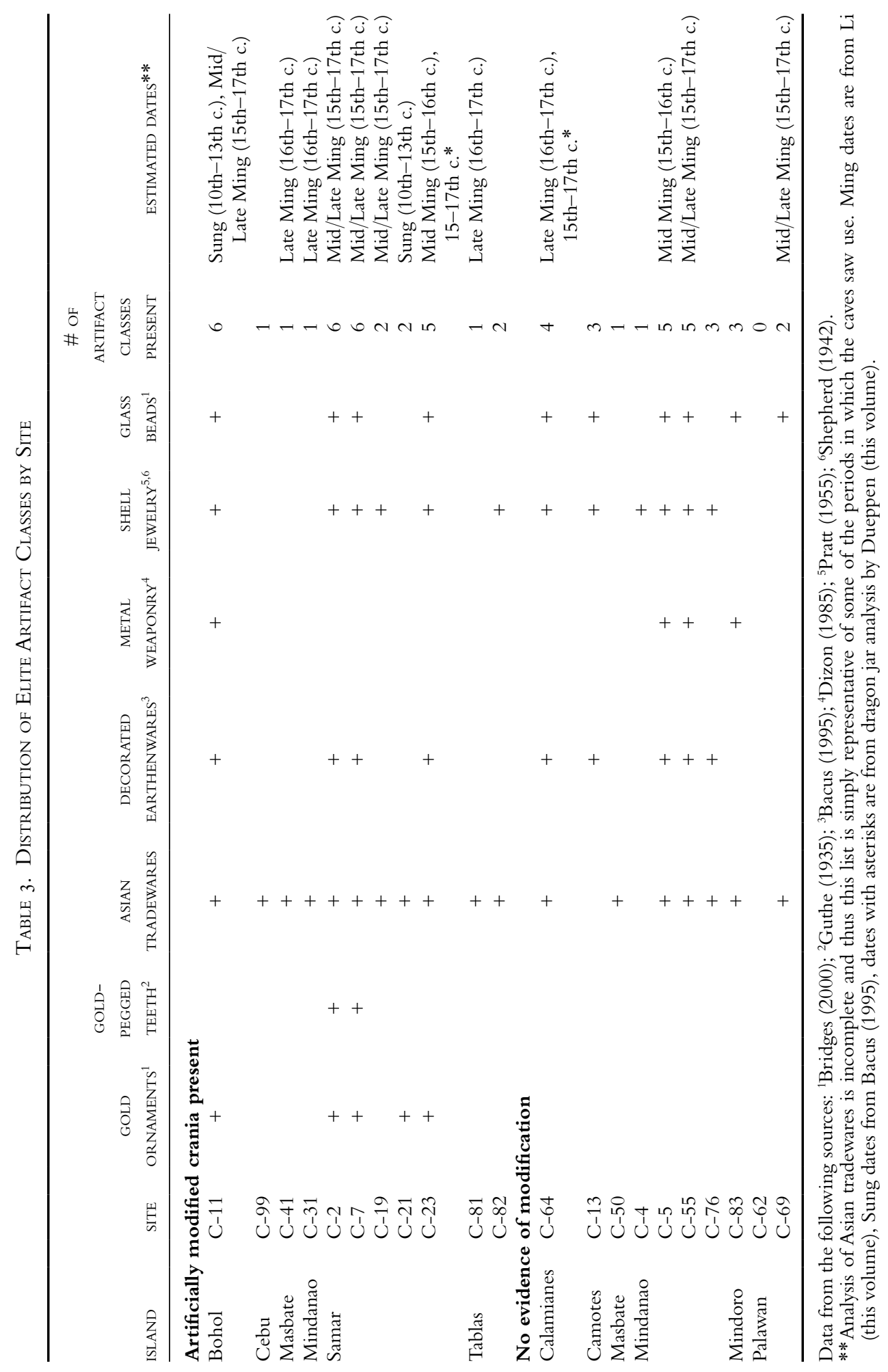


Table 4. Elite Artifact Classes: Presence/absence Data by Site Category and Results OF FISHER's EXACT TeST

\begin{tabular}{|c|c|c|c|c|c|}
\hline \multirow[b]{2}{*}{ ARTIFACT CLASS } & \multicolumn{2}{|c|}{$\begin{array}{l}\text { SITES WITH ACM } \\
\qquad(\mathrm{N}=\mathrm{I} \mathrm{I})\end{array}$} & \multicolumn{2}{|c|}{$\begin{array}{c}\text { SITES WITH NO } \\
\text { MODIFIED CRANIA } \\
(\mathrm{N}=\mathrm{IO})\end{array}$} & \multirow[b]{2}{*}{$P(\mathrm{ONE}-\mathrm{SIDED})$} \\
\hline & PRESENT & ABSENT & PRESENT & ABSENT & \\
\hline Gold ornaments & 5 & 6 & 0 & 10 & $0.023 *$ \\
\hline Gold-pegged teeth & 2 & 9 & 0 & 10 & 0.262 \\
\hline Asian tradewares & 11 & 0 & 7 & 3 & 0.090 \\
\hline Decorated earthenwares & 4 & 7 & 5 & 5 & 0.425 \\
\hline Metal weaponry & 1 & 10 & 3 & 7 & 0.256 \\
\hline Shell jewelry & 6 & 5 & 6 & 4 & 0.575 \\
\hline Glass beads & 4 & 7 & 6 & 4 & 0.260 \\
\hline
\end{tabular}

* significant at $\alpha=.05$.

only a single artifact class (gold ornaments) shows a significant result, which again suggests that the practice of ACM was not limited to the elite. Alternatively, these results could indicate that the distribution of "elite" goods was not as restricted as previously believed. This would be in line with Li's (this volume) proposal that there was a weak expression of wealth distinctions among the populations who utilized the burial caves.

Taken together, these analyses provide little evidence to support the claim that ACM was solely an elite practice in the central and southern Philippines. Although a modified cranium may have been considered a sign of nobility, and the elite may have relayed this to early European chroniclers, it is possible that lower-status parents chose to emulate the elite by modifying their children's heads in similar ways (Hoshower et al. 1995). However, it is important here to return to the caveat mentioned earlierour current lack of knowledge about which populations utilized the burial caves. One might question whether use of burial caves was restricted to the elite-in such a case the lack of distinction between caves with and without evidence for ACM would not necessarily imply that the practice of deformation was more widespread than previously believed. I could not locate any sources that suggested that the use of caves was restricted to the elite. Junker (1999), however, suggests that "Metal Age" burial caves (dating from the first millennium B.C. to the first millennium A.D.) provide evidence of wealth distinctions since some contain burial goods while others do not (Dizon 1979; Fox 1970, cited in Junker 1999). Even if use of the caves was restricted to the elite, it would imply that a simple correlation between elite status and ACM is not appropriate, as a majority of the crania in this study showed no evidence for modification.

\section{CONCLUSIONS}

Given its regional scope and relatively good provenience information, the Guthe Collection offers a rare opportunity to examine both the spatial distribution and the cultural context of ACM in the central and southern Philippines. Before examining the context of artificial deformation, however, it was first necessary to classify the cranial sample into deformed and undeformed groups. This was done through a com- 
bination of visual classification and discriminant function analysis. Visual classification resulted in the division of the crania into four groups - unmodified, modified, round frontal/flat occipital, and ambiguous. Discriminant function analysis largely confirmed visual classification, although the conservative nature of the function resulted in three crania being classified as unmodified that had been visually classified as artificially modified. Given that all of the crania placed in the "round frontal/flat occipital" class scored as unmodified, these crania were combined with the unmodified category for the remainder of the analyses reported here. Future work with this collection should include an analysis of the distribution and context of the crania displaying this occipital flattening, which may be the result of cradle boarding.

Given that the skeletal remains in the Guthe Collection were not collected systematically, interpretations regarding the spatial distribution of ACM are somewhat restricted. However, as has been documented in other studies (e.g., Koeze 1903-1904), modified crania were more common in the Visayan group. Furthermore, the islands of Samar and Tablas not only had the greatest percentage of artificially modified crania (among islands with a sample size greater than one), but they also were the only two islands from which crania of ambiguous modification status were recovered, indicating that the practice of ACM may have been more prevalent among populations from these two islands than others.

In considering the cultural context of the practice of ACM, this study has highlighted the need for greater chronological control over the sample. More refined dates would allow for both an examination of the distribution of ACM over time as well as more confidence in the identification of certain artifact classes as elite goods. Despite these limitations, the available evidence suggests that the practice of ACM in the central and southern Philippines was not restricted to the elite. It may be that artificial modification was practiced solely for aesthetic reasons. However, it is also possible that the practice may have served to define membership in some sort of horizontal social grouping. Future work on cranial samples with more detailed contextual information will be necessary in evaluating this possibility.

\title{
ACKNOWLEDGMENTS
}

I would like to thank Milford Wolpoff for his helpful comments, Veronique Belisle for translating the passage from Dingwall, and Carla Sinopoli for providing the base map and access to Guthe's field notes. I would also like to thank John Speth and the three anonymous reviewers for their useful comments on earlier drafts of this article; any mistakes that remain are, of course, my own. Research was supported by a National Science Foundation Graduate Research Fellowship.

\section{NOTE}

1. See Clark et al. 2007 for a detailed description of this process.

\section{REFERENCES CITED}

\author{
Aga-Oglu, Kamer \\ 1946 Ying Ch'ing porcelain found in the Philippines. Arts Quarterly 9:314-327. \\ 1948 Ming export blue and white jars in the University of Michigan. Arts Quarterly 11:201-217. \\ 1961 Ming porcelain from sites in the Philippines. Asian Perspectives 5:243-251.
}


ANDAya, BARbara

1992 Political development between the 16th and 18th centuries, in The Cambridge History of Southeast Asia, vol. I: From Early Times to c. 1800:402-459, ed. N. Tarling. Cambridge: Cambridge University Press.

Antón, Susan C., and Karen J. Weinstein

1999 Artificial cranial deformation and fossil Australians revisited. Journal of Human Evolution $36: 195-209$.

Bacus, Elisabeth A.

1995 Political Economy and Interaction: Late Prehistoric Polities in the Central Philippine Islands. Ph.D. diss. University of Michigan, Ann Arbor.

Beyer, H. OTLEy

1947 Outline review of Philippine archaeology by islands and province. Philippine Journal of Science $77: 205-374$.

Blackwood, Beatrice, and P. M. Danby

1955 A study of artificial cranial deformation in New Britain. The Journal of the Royal Anthropological Institute of Great Britain and Ireland 85:173-191.

Blom, Deborah E.

2005 Embodying borders: Human body modification and diversity in Tiwanaku society. Journal of Anthropological Archaeology $24: 1-24$.

Boas, Franz

1891 Second General Report on the Indians of British Columbia. Report of the Sixtieth Meeting of the British Association for the Advancement of Science, 562-715.

Bridges, Elizabeth

2000 Beads in archaeological contexts: Philippine adornments from the Guthe Collection. Unpublished manuscript, Asian Division, Museum of Anthropology, University of Michigan.

Clark, Jamie L., Seth D. Dobson, Susan C. Antón, John Hawks, Keith L. Hunley, and Milford

H. WOLPOFF

2007 Identifying artificially deformed crania. International Journal of Osteoarchaeology 17:596-607.

Dingwall, Eric J.

1931 Artificial Cranial Deformation: A Contribution to the Study of Ethnic Mutilation. London: John Bale, Sons and Danielson, Ltd.

Dizon, EusEBio

1979 Tigkiw Na Saday: A Jar Burial Site. Philippine National Museum Anthropological Papers No. 2. Manila: Philippine National Museum Publications.

1985 Metallurgical analysis of iron artifacts in the Guthe Collection. Unpublished records on file, Asian Division, Museum of Anthropology, University of Michigan.

Fletcher, Alexandra, Jessica Pearson, and Janet Ambers

2008 The manipulation of social and physical identity in the pre-pottery Neolithic: Radiographic evidence for cranial modification at Jericho and its implications for the plastering of skulls. Cambridge Archaeological Journal 12:309-325.

FOX, ROBERT

1970 The Tabon Caves. Manila: National Museum Publications.

Friess, Martin, and Michel Baylac

2003 Exploring artificial cranial deformation using elliptic Fourier analysis of Procrustes aligned outlines. American Journal of Physical Anthropology 122:11-22.

GARRETT, JOHN

1988 Status, the warrior class and artificial cranial deformation, in The King Site: Continuity and Contact in Sixteenth Century Georgia: 35-46, ed. R. L. Blakely. Athens: University of Georgia Press.

Guthe, Carl E.

1922- Unpublished field notes, University of Michigan Philippine Expedition. Asian Division,

1925 Museum of Anthropology, University of Michigan.

1927 The University of Michigan Philippine Expedition. American Anthropologist 29:69-76.

1929 Distribution of sites visited by the University of Michigan Philippine Expedition 1922-1925. Papers of the Michigan Academy of Science, Arts, and Letters 10:79-89. 
1935 Gold-decorated teeth from the Philippine Islands. Papers of the Michigan Academy of Science, Arts, and Letters 20:7-23.

Hoshower, Lisa M., Jane E. Buikstra, Paul S. Goldstein, and Ann D. Webster

1995 Artificial cranial deformation at the Omo M10 site: A Tiwanaku complex from the Moquegua Valley, Peru. Latin American Antiquity 6:145-164.

JONES, SiAN

1997 Archaeology of Ethnicity: Constructing Identities in the Past and Present. London: Routledge.

JUNKer, LAURA L.

1999 Raiding, Trading, and Feasting: The Political Economy of Philippine Chiefdoms. Honolulu: University of Hawai'i Press.

Keswani, Priscilla F. S.

1989 Mortuary Ritual and Social Hierarchy in Bronze Age Cyprus. Ph.D. diss. University of Michigan, Ann Arbor.

Koeze, G. A.

1903- Crania Ethnica Philippinica: Ein Beitrag zur Anthropologie der Philippinen. Haarlem: H. Keinmann 1904 \& Co.

Lozada Cerna, Maria C.

1998 The Senorio of Chiribaya: A Bioarchaeological Study in the Osmore Drainage of Southern Peru. Ph.D diss. University of Chicago.

MacDonald, William K.

1972 Preliminary archaeological investigation of burial caves in the Upper River Area, Southwestern Samar. Leyte-Samar Studies 6:30-42.

Maceda, Marcelino N.

1973 Some remarks on artificial cranial deformation. Philippine Quarterly of Culture and Society $1: 58-59$.

Macherroni, Michael J.

2006 The Archaeology of Globalisation and Mainland Southeast Asia, 1570-1640 AD. Ph.D. diss. University of New England, Armidale NSW, Australia.

O'Loughlin, Valerie D.

2004 Effects of different kinds of cranial deformation on the incidence of Wormian bones. American Journal of Physical Anthropology 123 : 146-155.

Pratt, Peter P.

1955 Addendum to Mary Shepherd's Article "Shell Bracelets in the Philippines." Unpublished manuscript on file. Asian Division, Museum of Anthropology, University of Michigan.

SHEPHERD, MARY

1942 Shell Bracelets from the Philippines. Unpublished manuscript on file. Asian Division, Museum of Anthropology, University of Michigan.

Sinpoli, Carla M., Stephen Dueppen, Robert Brubaker, Christophe Descantes, Michael D.

Glascock, Will Griffin, Hector Neff, Rasmi Shoocongdej, and Robert J. Speakman

2006 Characterizing the stoneware "dragon jars" in the Guthe Collection: Chemical, decorative, and formal patterning. Asian Perspectives 45(2):240-282.

Stark, Miriam T., ED.

1998 The Archaeology of Social Boundaries. Washington, D.C.: Smithsonian Institution Press.

Suzuki, Hisashi, Yuji Mioguchi, and Eduardo Conese

1993 Craniofacial measurements of artificially deformed skulls from the Philippines. Anthropological Science: Journal of the Anthropological Society of Nippon 101:111-127.

Tenazas, Rosa C. P.

1973 The boat-coffin burial complex in the Philippines and its relation to similar practices in SE Asia. Philippine Quarterly of Culture and Society 1:19-25.

Torres-Rouff, Christina

2002 Cranial vault modification and ethnicity in Middle Horizons San Pedro de Atacama, Chile. Current Anthropology 43:163-171. 
Torres-Rouff, C., And L. T. Yablonsky

2005 Cranial vault modification as a cultural artifact: A comparison of the Eurasian steppes and the Andes. Homo: Journal of Comparative Human Biology 56:1-16.

Trinkaus, ERIC

1982 Artificial cranial deformation in the Shanidar 1 and 5 Neandertals. Current Anthropology 23:198-199.

\begin{abstract}
Given its regional scope and good provenience information, the Guthe Collection offers a rare opportunity to examine both the spatial distribution and the cultural context of artificial cranial modification (ACM) in the archaeological record of the central and southern Philippines. A combination of visual classification and discriminant function analysis was used to classify the cranial sample into modified and unmodified groups. Following this, the relative frequency of each class of crania by island was explored. The results show that 95 percent of the artificially modified crania in this sample were recovered from the Visayan group, and most of these were found on the islands of Samar and Tablas. Not only did these two islands have the greatest percentage of modified crania (among islands with a sample size greater than one), they were also the only islands from which crania of ambiguous modification status were recovered. On the basis of these results, it would appear that the practice of ACM may have been more common among historic populations on Samar and Tablas than on other islands in the study region. Statistical tests were then conducted in order to explore the hypothesis that cranial modification was an elite practice. The available evidence suggests that the practice of ACM in the central and southern Philippines was not limited to members of the social elite. Keywords: cranial modification, cranial deformation, Philippines, burials.
\end{abstract}

